\title{
Prudência ou preconceito? 0 impedimento da doação de sangue por homens que fazem sexo com homens
}

Prudence or prejudice? Preventing the donation of blood by men who have sex with men

¿Prudencia o prejuicio? El impedimento de la donación de sangre por hombres que tienen sexo con hombres

Sandra Mara Campos Alves ${ }^{1}$

Moacyr Rey Filho ${ }^{2}$

Tramita, na mais alta Corte do Poder Judiciário Brasileiro, ação judicial que busca declarar inconstitucional normativas emitidas pelo Ministério da Saúde (MS) e Agência Nacional de Vigilância Sanitária (Anvisa) que tornam inaptos para doação de sangue, por um período de 12 (doze) meses, homens que tiveram relações sexuais com outros homens (HSH) (1) (2) (3).

A justificativa apresentada pelos órgãos públicos para tal vedação se fundamenta no interesse coletivo de garantir uma maior segurança transfusional para os receptores de sangue, tendo em vista os possíveis riscos de transmissão de doenças pelo sangue, especialmente o HIV/AIDS, que são majorados quando relacionados ao grupo de HSH (1).

Aos que são contrários, se alega que tais previsões são discriminatórias, fruto da estigmatização da comunidade gay, gera desigualdade jurídica entre as pessoas, e atenta ao princípio da dignidade da pessoa humana (1).

No campo da saúde, historicamente se persegue a redução do risco e o aumento da segurança nos inúmeros procedimentos e ações que nele se desenvolvem. Na área da hemoterapia, o ordenamento jurídico-sanitário brasileiro prevê medidas que visam um aumento da segurança transfusional, e consequente redução dos riscos sanitários, com especial atenção para situações ou comportamentos que possam majorar o risco de infecções transmitidas pela via sexual, sejam elas provenientes de práticas homossexuais ou heterossexuais (2) (3).

\footnotetext{
1 Advogada, Doutoranda em Saúde Coletiva, Universidade de Brasília, Brasília - DF, Brasíl. E-mail: smcalves@gmail.com

${ }^{2}$ Ministério Público do Distrito Federal e Territórios.
} 
A prática de ato sexual em troca de dinheiro ou droga; sexo com um ou mais parceiros ocasionas ou definitivos; sexo com pessoas portadoras de infecções transmissíveis pela via sexual e sanguínea são algumas das situações previstas em lei que geram inaptidão temporária ao candidato que deseje doar sangue (2) (3).

De forma complementar, a legislação prevê ainda que durante a entrevista, ato que integra a fase preliminar de seleção dos doadores, sejam dirigidas perguntas que versem sobre situações ou comportamentos que levem a risco acrescido para infecções sexualmente transmissíveis, devendo ser excluídos da seleção quem os apresentar (2).

Contudo, é importante marcar que mesmo com todos os avanços da medicina, e a constante adoção de novos padrões de qualidade que permitam reduzir os riscos advindos da transfusão de sangue, sejam eles imediatos ou tardios, ainda não é possível garantir um processo de transfusão isento de riscos (4) (5).

Luhmann (6) em sua obra Sociologia del Riesgo, já apontava que o avanço científico e tecnológico vivenciado nas sociedades modernas, ao invés de mitigar as probabilidades de risco, complexifica o seu cálculo, vez que se tem acesso a uma abundância de possibilidades de investigação e conhecimentos antes inexistentes. Com isso, há uma ampliação das percepções de risco, ao invés do alcance da segurança.

Nesse sentido, a busca por um padrão de segurança transfusional inatingível, com a tentativa de controle de todas as multicausalidades possíveis que poderiam interferir na qualidade do sangue coletado por meio de doação, não pode ser justificativa para restringir direitos individuais, ou gerar desigualdade jurídica. Ao contrário, em um Estado democrático de direito, atos que implicam na restrição de direitos individuais devem sempre ser vistos como medidas de exceção, e, quando necessária a sua aplicação, os princípios da proporcionalidade e razoabilidade devem traçar o seu contorno (7) (8).

Durante os anos de 1980, com o surgimento da epidemia de HIV/AIDS, voltou-se os olhos à comunidade gay e suas práticas sexuais, tendo em vista a alta prevalência da doença nesse grupo, especialmente entre os homens, e a possibilidade do contágio por meio da transfusão de sangue. Inicialmente foi nominada de "doença da imunodeficiência gay", ou "gay-related immunodeficiency (GRID) (9).

Todavia, o conhecimento científico sobre as formas de contágio e transmissão do HIV/AIDS avançou, e um dos principais ganhos foi saber que a doença não escolhe nenhum grupo específico, conduzindo a uma alteração nas campanhas de prevenção da 
doença, com ênfase na utilização de mecanismos de barreira (camisinhas) quando da realização do ato sexual.

Assim, é desarrazoado que mesmo com esse conjunto de evidências científicas, aliadas aos procedimentos acautelatórios dispostos na legislação sobre doação de sangue, ainda se queira impingir um agravo desnecessário a um grupo específico - $\mathrm{HSH}$ - tendo em vista sua orientação ou prática sexual.

Enquanto a mesma legislação prevê que o doador heterossexual tenha como única condição a realização de sexo com parceira fixa nos últimos 12 (doze) meses, sem menção ao uso do preservativo, para o grupo de $\mathrm{HSH}$, essa possibilidade sequer foi cogitada, o que vem gerando profunda desigualdade jurídica entre os dois grupos.

$O$ ato de doar sangue, além de significar uma ação altruísta, é expressão de cidadania e exercício de direitos. A Organização Mundial da Saúde - OMS preconiza que o grupo de doadores de sangue mais seguros são formados por voluntários regulares, não remunerados, pois apresentam a menor prevalência de doenças infecto contagiosas transmitidas pelo sangue (10).

No Brasil, a manutenção de estoques de sangue nos estabelecimentos de saúde é preocupação recorrente dos 27 hemocentros existentes no país, e por isso mesmo, inúmeras campanhas são produzias e veiculadas em busca da captação e/ou fidelização de doadores, visto ser a única forma de se assegurar um estoque suficiente de sangue.

Dados da OMS apontam que apenas 57 países conseguem coletar $100 \%$ do seu suprimento de sangue por meio de doações voluntárias, não remuneradas. Ao passo que 71 países apresentam menos de $50 \%$ de seu suprimento atendidos por doações voluntárias (10).

Assim, a expulsão dessa regra do ordenamento jurídico pátrio representará não apenas o reequilíbrio de direitos, mas um importante ato de combate ao preconceito.

\section{REFERÊNCIAS}

1. Supremo Tribunal Federal. Ação Direta de Inconstitucionalidade no 5543/DF. Disponível em: http://www.stf.jus.br/portal/processo/verProcessoAndamento.asp?incidente=4996495 Acesso em 15.11.2017.

2. Ministério da Saúde. Portaria $\mathrm{n}^{\circ}$ 158, de 4 de fevereiro de 2016 . Redefine o regulamento técnico de procedimentos hemoterápicos. República Federativa do Brasil. Disponível em: 
http://portalarquivos.saude.gov.br/images/pdf/2016/abril/12/PORTARIA-GM-MS-N1582016.pdf Acesso em 15.11.2017.

3. Agência Nacional de Vigilância Sanitária (ANVISA). Resolução da Diretoria Colegiada RDC no 34, de 11 de junho de 2014. Dispõe sobre as boas práticas do ciclo de sangue. República Federativa do Brasil, Brasília, DF, 16 de jun. 2014. Disponível em: http://portal.anvisa.gov.br/documents/10181/2867975/RDC 342014 COMP.pdf/283a192e -eee8-42cc-8f06-b5e5597b16bd?version=1.0 Acesso em 15.11.2017.

4. Araújo ESA, Barone AA. Sangue seguro: mito ou realidade? Revista Brasileira de Hematologia e Hemoterapia, 2008, 30(5):350-351.

5. Garrazone CFV, Brito AM, Gomes YM. Importância da avaliação sorológica prétransfusional em receptores de sangue. Revista Brasileira de hematologia e Hemoterapia. São Paulo, 2004, 26:93-98.

6. Luhmann N. Sociologia del riesgo. Guadalajara: Walter der Grurter Co., 1992.

7. Canotilho JJ. Direito Constitucional e Teoria da Constituição. Coimbra: Almedina, 2017.

8. Silva VA. Direitos fundamentais: conteúdo essencial, restrições e eficácia. São Paulo: Malheiros, 2010.

9. Altman LK. New homosexual desorder worries health officials. The New York Times. 11 de maio de 1982; Science. Disponível em:

https://warwick.ac.uk/fac/arts/english/currentstudents/undergraduate/modules/fulllist/special len304/student work/new homosexual disorder worries health officials - nytimes.pdf Acesso em 17.11.2017.

10. Organización Mundial de la Salud. 10 datos sobre las transfusiones de sangre. Disponível em: http://www.who.int/features/factfiles/blood transfusion/es/ Acesso em 30.10. 2017.

\section{Como citar este artigo:}

Alves SMC, Rey Filho M. Prudência ou preconceito? O impedimento da doação de sangue por homens que fazem sexo com homens. Revista Cadernos Ibero-Americanos de Direito Sanitário. 2018 abr./jun, 7(2):262265. 